\title{
Causal properties and conservative reduction 1
}

\author{
Michael Esfeld, University of Lausanne, Department of Philosophy \\ Michael-Andreas.Esfeld@unil.ch \\ (forthcoming in Philosophia Naturalis 47 (2010))
}

\begin{abstract}
The paper argues in favour of (1) a causal-functional theory of all properties including the physical ones and (2) a conception of properties as tropes or modes in the sense of particular ways that objects are. It shows how these premises open up a version of functionalism according to which the properties on which the special sciences focus are identical with configurations of physical properties and thereby causally efficacious without there being any threat of eliminativism.
\end{abstract}

\section{The dilemma of functionalism}

Since the 1970s, functionalism has been the standard position with respect to the special sciences such as, in particular, biology and psychology. Functionalism seems to be able both to show how the special sciences and the entities they deal with are related to fundamental physics and to pay heed to their specific character. Since the 1990s, however, serious doubts have been raised as to whether functionalism can really achieve that target. The aim of this paper is to set out a version of functionalism that starts from the idea that all properties in the world are functional in the sense of causal properties and that avoids on this basis the pitfalls of both epiphenomenalism and eliminativism. I first point out the dilemma of epiphenomenalism and eliminativism into which the standard versions of role and realizer functionalism run (this section) and then argue in favour of the causal theory of properties (section 2). On this basis, I draw the consequence of a conservative ontological reductionism (section 3). Finally, I maintain that ontological and epistemological reductionism stand or fall together (section 4).

Mainstream functionalism as conceived notably by Hilary Putnam (1967/1975) and Jerry Fodor (1974) regards the properties on which the special sciences focus as causal roles that are realized by configurations of physical tokens (role functionalism). For instance, a gene type consists in a causal role, such as to produce proteins of a certain type, and that role can be realized by different types of DNA configurations in certain molecular contexts. Role functionalism thus binds the property types on which the special sciences focus to the physical domain through realization and establishes at the same time their specific character through multiple realization, which prevents them from being identical with physical types.

Nonetheless, role functionalism faces the same problem as the theory of non-physical, emergent properties, namely that it is not intelligible how the role properties can be causally efficacious. According to role functionalism, the functional properties that are the subject matter of the special sciences are causal roles, defined by a characteristic pattern of effects each. However, the role properties as such are not causally efficacious. It is the properties that carry out the role, the physical properties, that bring about the effects in question. In other words, the presence of functional role properties indicates that there are other properties, the

1 The claims made in this paper are elaborated on in a more detailed manner in Esfeld and Sachse, 2010, chapter 2. I'm grateful to an anonymous referee for criticism of the draft of this paper. 
physical realizer properties, that produce certain effects. Hence, if one conceives the functional properties that are the subject matter of the special sciences as role properties, being distinct from realizer properties, one faces the consequence that these functional properties are epiphenomenal. Only the physical realizer properties are causally efficacious (cf. Block, 1990).

One may attempt to avoid this consequence by invoking systematic overdetermination (see notably Bennett, 2003, and Loewer, 2007). The idea is that both the role properties and the realizer properties figure in the relevant causal relations so that one and the same effect - such as the production of certain proteins - is overdetermined by two causes that are not identical with one another, such as genes and molecular sequences of bases. There is systematic overdetermination because any physical effect of a role property is caused at the same time by the realizer property in question - and given supervenience, there is a sufficient physical cause for any effect whatsoever that a role property causes. The proponents of this idea maintain that such systematic overdetermination is acceptable since the role properties strongly supervene on the realizer properties. Strong supervenience is to say that the existence of the physical realizer properties is a metaphysically sufficient condition for the existence of the functional role properties in question.

Strong supervenience is sufficient to make certain counterfactual propositions true. Suppose that in a situation in which a physical effect $p_{2}$ has both a sufficient mental cause $m_{1}$ and a sufficient physical cause $p_{1}$, the proposition "If $p_{1}$ had not occurred, $p_{2}$ would not have occurred either" is a true counterfactual. Then, by strong supervenience, the proposition "If $m_{1}$ had not occurred, $p_{2}$ would not have occurred either" is a true counterfactual as well, since there is no possible world in which there is a counterpart of $p_{1}$ without there being also a counterpart of $m_{1}$. However, we need an argument why that latter counterfactual should express a causal relation. In other words, we need an argument why strong supervenience on its own should exclude epiphenomenalism, that is to say, should exclude that a property which strongly supervenes on another property can be epiphenomenal. The mere fact of a property strongly supervening on another property cannot constitute a sufficient reason for claiming that the supervenient property also causes - some - of the effects that the subvenient property has so that these effects are overdetermined (see Esfeld, 2010). Such a claim would amount to simply stipulating that properties which strongly supervene on other properties cannot be epiphenomenal, without offering any argument.

Since Jaegwon Kim (1998) has laid stress on the problem of the causal efficacy of the functional properties on which the special sciences focus, the reductionist version of functionalism, the realizer functionalism that goes back mainly to David Lewis (see Lewis, 1994, for a summary), has gained in popularity and is to a certain extent favoured by Kim himself (Kim, 1998, and, 2005). Like role functionalism, realizer functionalism starts from the functional descriptions that the special sciences use. However, whereas role functionalism conceives these descriptions as being about causal role properties that are second order properties, realizer functionalism takes them to refer to the physical realizer properties. It conceives the descriptions of the world that the special sciences offer as functional descriptions, being fulfilled or realized by in the last resort configurations of microphysical tokens. In his metaphysics of Humean supervenience, Lewis (1986a, introduction) regards the fundamental physical properties as perfectly natural, purely qualitative and intrinsic properties that occur at space-time points. Everything else that there is in the world supervenes on the 
distribution of the fundamental physical properties in space-time in the sense that it is a feature of that distribution. There is nothing over and above that distribution, it being sufficient to make true all the truths about the world. In particular, the descriptions (theories, laws) that the special sciences offer are true in virtue of certain features of contingent regular co-occurrence or counterfactual dependence in the distribution of the fundamental physical, purely qualitative properties as a whole. In a nutshell, there are no functional properties of the special sciences, but only categorical properties of physics. Nonetheless, the functional descriptions of the special sciences are true. The distribution of the categorical properties in space-time makes them true. Lewis' realizer functionalism thus provides for truthmakers of the functional descriptions of the special sciences without being committed to recognizing functional properties that exist in the world.

Consequently, multiple realization is construed as an epistemological rather than an ontological feature. Multiple realization means that the functional descriptions of the special sciences refer multiply in the following sense: descriptions of one and the same type of a special science refer to physical configurations that come under different physical types due to their differences in composition. These configurations of categorical, physical properties all make true descriptions of a certain functional type, without having anything physical in common that distinguishes them from all the other physical configurations that do not make a functional description of the type in question true.

By way of consequence, it is, however, questionable how these functional descriptions can have a scientific quality. All the effects that the physical configurations that make these descriptions true can have possess complete physical causes and can therefore be explained exclusively in physical terms. If the functional descriptions of the special sciences are not about genuinely functional properties, but refer to configurations of categorical, physical properties and if these configurations do not have anything physical in common that distinguishes them from all the other configurations, then it is not intelligible what contribution to a scientific account of the world the functional descriptions of the special sciences could make that is not already provided for by physics.

Conceiving multiple realization in that manner as multiple reference can therefore also be received as an invitation to construct on the basis of a fundamental and universal physical theory several specific physical theories that map the special science theory in question for a particular domain or species in which there is uniform realization - e.g. one specific theory that maps the psychological theory of pain in the case of humans, another specific theory that maps the psychological theory of pain in the case of octopuses, etc. (see Lewis, 1980, and Kim, 1998, 93-95, as well as Bickle, 1998). Each of these physical theories then takes the place of the special science theory for a particular domain or species. Hence, there is then nothing left in which the scientific quality of the theories of the special sciences could consist.

In sum, realizer functionalism adopts an eliminativist attitude with respect to the functional properties in which the special sciences deal. The descriptions (laws, theories) of these sciences are nevertheless true, being made true by physical configurations. However, this eliminativist attitude as regards the functional properties leads to the consequence that - due to multiple realization or, more precisely, multiple reference - the scientific quality of the special sciences is also eliminated. Only purely physical descriptions and theories that apply to particular, physically defined groups each and that are integrated into an encompassing physical theory belong in the last resort to a scientific account of the world. 
Functionalism as it stands thus faces a dilemma between epiphenomenalism (role functionalism as non-reductive physicalism) and eliminativism with respect to the scientific quality of the special sciences (realizer functionalism as reductive functionalism). Nonetheless, there is no other position visible that could take the place of functionalism. The two main non-functionalist alternative positions of either admitting non-physical emergent properties or of retreating to a physicalism that recognizes only physics obviously run into the mentioned dilemma as well - epiphenomenalism in the first case, eliminativism in the second one. This diagnosis suggests the following conclusion: functionalism still is an attractive position. However, it has to be spelled out in another manner than in the standard versions of role and realizer functionalism.

This paper takes the mentioned dilemma as a motivation for drawing the following two conclusions:

- It is wrong-headed to conceive an opposition between functional and physical properties (or functional and physical descriptions, respectively).

- It is wrong-headed to build anti-reductionist arguments on multiple realization.

On this basis, the paper seeks to make a first step towards overcoming that dilemma by proposing that all properties, including the physical ones, are functional properties in the broad sense of causal properties, and showing how this view of properties paves the way for a conservative reductionism.

\section{Causal properties}

Leaving aside the issue of qualia, let us take for granted that the special sciences' descriptions are functional descriptions and that, accordingly, the properties in which they trade are functional ones. Functional properties are causal properties. What they are consists notably in certain effects that they produce. Let us focus on the effects - the forward-looking causal features in Sydney Shoemaker's terms (see e.g. Shoemaker, 2007, chapter 2) - and let us leave open whether it is essential to a functional property to possess a certain causal history, thus simplifying the argumentation. In being causal properties, functional properties are dispositions: they consist in the disposition to produce certain effects. However, it does not follow that they are a subclass of dispositional properties; following Stephen Mumford (1998, chapter 9), one can rather maintain that all dispositional properties are causal-functional ones.

In contemporary philosophy, the causal theory of properties has been developed mainly in opposition to what is known today as Humean metaphysics (see notably Shoemaker, 1980, for that opposition). According to Humean metaphysics, properties are pure qualities whose essence is independent of the causal relations in which properties of a given type stand in a given world. Their essence thus is purely qualitative, being a primitive suchness, known as quiddity (that term has been introduced in the contemporary debate by Black, 2000). Consequently, that essence cannot be known; that consequence is known as humility (see e.g. Locke, 2009).

Quidditism is in a certain sense analogous to haecceitism. A haecceitistic difference is a difference between possible worlds which consists only in the fact that there are different individuals in two worlds, without there being any qualitative difference between the worlds in question. In other words, a haecceitistic difference is a difference between individuals which has the consequence that worlds have to be recognized as different, although they are indiscernible. If one maintains that the essence of properties is a primitive suchness (a 
quiddity), a similar consequence ensues: one is in this case committed to recognizing worlds as different that are identical with respect to all causal and nomological relations, but that differ in the purely qualitative essence of the properties that exist in them. A quidditistic difference thus is a qualitative difference between worlds due to which worlds have to be recognized as different, although they are indiscernible.

Consequently, there always automatically is multiple realizability or the possibility of multiple reference. Functional descriptions of one and the same type can be made true by configurations of intrinsic properties whose primitive suchness is entirely different, as long as the relations among these properties are such that they fulfil the functional descriptions in question against the background of the whole distribution of intrinsic and categorical properties in the world in question. Thus, for instance, the intrinsic properties that make true the fundamental physical description "negative elementary charge" in the real world can make true the fundamental physical description "mass $x$ " in another possible world, and vice versa. In other words, properties of one and the same type - possessing the same primitive suchness - can in one world fulfil the charge role and in another world the mass role. That is why one cannot deduce the nature of the realizer from the role.

David Lewis, the main proponent of Humean metaphysics in contemporary philosophy, has endorsed the consequences of quidditism and humility in one of his last papers (published in 2009). However, the discussion in the last decade has made increasingly clear that notably the commitment to quidditism is highly objectionable, in particular for a metaphysics that takes itself to be close to empiricism and inspired by science (see already Black, 2000; for a contrary view see Noonan, 2010): one has to acknowledge an essence of properties that is a pure quality and thus a primitive suchness, being detached from all causal and nomological relations and hence detached from anything of which it is possible to gain knowledge. This consequence is a good motivation for the causal theory of properties that ties the essence of properties to the causal relations in which they stand.

One can sum up the central claim of the latter in the following manner: in being certain qualities, properties are causal, namely powers to produce certain specific effects. Take charge for example. This is a fundamental physical property that can occur at space-time points. Charge is a certain quality that is distinct from, for instance, mass. Insofar as charge is a qualitative property, it is a power that manifests itself in certain causal relations, namely the power to generate an electromagnetic field, resulting in the attraction of opposite-charged and the repulsion of like-charged objects.

This view of properties is only coherent on the condition that one considers the qualitative and the causal character of properties as identical. These are not even different aspects of properties, but exactly one and the same. The position of C. B. Martin (1997) and John Heil (2003, chapter 11) is often read as a double aspect theory of properties - properties having a qualitative and a causal aspect - and is thus seen as standing in opposition to the position of Sydney Shoemaker (1980) and Alexander Bird (2007a). However, Heil (2009, 178) says with respect to Martin's last position that he finally conceived properties as "powerful qualities". Against that background, there is no substantial disagreement between the views of Martin and Heil on the one hand and Shoemaker (1980) and Bird (2007a) on the other.

If, by contrast, one interprets Martin and Heil as holding a double aspect theory, there are two obvious objections: what is the relationship between the qualitative and the causal aspect of a property? How can the objection of quidditism be avoided as regards the purely 
qualitative aspect of properties? There is only one reasonable position in this context, namely the one that conceives properties as being causal in being certain qualities: properties that are purely causal without being certain qualities would be pure potentialities instead of being real, actual properties (cf. the objection of Armstrong 1999, section 4). And properties that are certain qualities without these qualities being certain causal powers would be quiddities, committing us to recognize worlds that are indiscernible as being qualitatively different nonetheless.

Properties that are causal powers in being certain qualities are dispositions. If this theory applies to all properties, the fundamental physical properties are dispositions as well. This view therefore implies that dispositions do not presuppose a categorical basis. However, if one conceives dispositional properties as being certain actual qualities, it is no problem that there are no underlying categorical bases. One would run into a problem if and only if one conceived dispositions as pure potentialities, which are not actual properties as such, but presuppose a categorical basis (cf. Bird, 2007b, 519-523).

If one regards properties as causal in being certain qualities, one can nevertheless maintain that properties are in a certain sense intrinsic. It is a fact about an object in itself, independently of other objects, that it has certain powers in having certain qualities. This fact is independent of whether the object in question is alone or accompanied by other objects (cf. the definition of intrinsic properties by Langton and Lewis 1998). Charge, for instance, may be an intrinsic and qualitative property inhering in an object and at the same time a causal property, since the qualitative nature of this property consists in generating an electromagnetic field, resulting in the attraction of opposite-charged and the repulsion of likecharged objects.

Even if properties are causal, the relata of causal relations can be objects or events. Causal relations obtain between objects or events in virtue of their properties. That the properties are causal is to say the following: insofar as an object or event has certain properties, it has certain powers. The causal relations that consist in the production of these effects are metaphysically necessary in the following sense: in any possible world in which there are properties of the types in question, there are also causal relations of these types. Thus, in any possible world in which there is charge, charged objects generate an electromagnetic field, resulting in the attraction of opposite-charged and the repulsion of like-charged objects. In short, one can make a sound metaphysical case for all properties being functional properties in the sense of causal properties that is independent of the debate about the mentioned dilemma of functionalism. This is important in view of the project to apply the causal theory of properties in order to overcome the mentioned dilemma of functionalism.

We have to mention briefly another issue in the metaphysics of properties: let us conceive properties as particulars (tropes or modes) instead of universals. I prefer the term "mode" to the term "trope", since it does not suggest a commitment to the bundle view of objects, expressing instead the idea that properties are the ways in which the objects are (cf. Heil, 2003, chapter 13, as well as Strawson, 2008). Again, there are independent arguments available for that conception. Suffice it here to hint at the following two ones: (1) The instantiation relation that is supposed to hold between universals and particulars is unclear. If properties exist as universals beyond the empirical world, it is unclear how what there is in the empirical world can participate in them (see already Plato, Parmenides, 130e-133a). If properties exist as universals in the empirical objects, it is not intelligible how numerically 
one and the same universal can be instantiated in many different objects. (2) As far as the fundamental physical properties are concerned, one can maintain that there is no need to posit universals in order to account for the similarities among them, since these similarities amount to qualitative identities. This qualitative identity is the basis for all further significant, objective similarities in the world.

For instance, all modes of negative elementary charge in the world are exactly the same, that is, qualitatively identical. By the same token, all the modes that are a certain value of rest mass are qualitatively identical. By modes, I always mean determinate properties and not determinable ones - that is, not properties such as, for instance, elementary charge or rest mass, but e.g. negative elementary charge and rest mass $0,51 \mathrm{MeV}$. All electrons in the world constitute a natural kind, because their characteristic properties - negative elementary charge and rest mass $0,51 \mathrm{MeV}$ - are exactly the same (see Busse, 2008, for an elaborate position in this sense). Fundamental physical properties in the sense of modes hence are numerically distinct, but qualitatively identical. All and only those fundamental physical modes that are qualitatively identical make true the same description (concept, predicate) that expresses what these properties are - such as "negative elementary charge" or "rest mass 0,51 MeV". In sum, there are qualitative identities among fundamental physical modes that are sufficient to ground the similarities that there are among more complex properties, including the ones on which the special sciences focus.

\section{Conservative identity of properties}

Conceiving all properties (1) in a causal-functional way and (2) as particulars (modes) enables us to maintain that the properties in which the special sciences trade exist and are identical with physical properties (see also Whittle, 2008, as regards these two premises and their consequences; see furthermore the position that Gillet, 2007, describes as continuity functionalism). More precisely, they are identical with the manner in which certain microphysical objects are related with one another, producing certain specific effects as a whole under certain environmental conditions due to the manner in which they are arranged; by a configuration of physical properties, we mean such relations among microphysical objects. The reason for this identity is that both are causal-functional: the properties on which the special sciences focus consist in producing certain effects, and these effects are identical with the effects that certain physical configurations bring about as a whole in certain environments. It is therefore not possible to tell them apart on a causal basis. For instance, a certain gene produces certain proteins, and these proteins are identical with the effects that a certain DNA configuration brings about as a whole in a specific molecular context. More precisely, certain atoms are related in a certain way, forming a configuration of nucleic acids of a certain molecular type, and in virtue of the way in which they are related, they produce certain proteins and are therefore identical with a gene of a certain type.

There is no reason to distinguish between role and realizer properties when both are causalfunctional and when properties are modes. The way a complex object is qua being a certain biological or mental, functional property token is the same as the way the complex object in question is qua being a certain physical configuration if and only if the effects that the object brings about qua being the former are identical with the effects that the object brings about qua being the latter. We hence get from a theory of causal-functional properties all the way down to a conservative, ontological functional reduction: all the properties that there are in 
the world are either themselves fundamental physical, causal-functional properties or are identical with configurations of such properties. This position is a reductionism, since all the properties are physical, but only some are also biological, or mental. It is conservative, since there are biological and mental properties, etc. with all their specific causal features out there in the world (see Esfeld, 2007, for an argument showing that the causal theory of properties does justice to our experience of mental causation).

An argumentation in this vein is often supposed to run into the following problem: if one maintains that the properties of complex objects on which the special sciences focus are identical with physical properties, then there is the danger of this position ending de facto up in an eliminativism with respect to these properties of complex objects, because even given the premise of identity, it is not able to show how these properties can be causally efficacious. However, this problem cannot be simply a consequence of the claim of identity: identity is a logical relation that is symmetric. If the causally efficacious properties that complex objects have as a whole are identical with a configuration of fundamental physical properties, then some such configurations are causally efficacious properties of complex objects as a whole. In general, if all $A \mathrm{~s}$ are identical with $B \mathrm{~s}$, then some $B \mathrm{~s}$ are identical with $A$ s. It does not make sense to ask whether a given complex object brings about certain effects qua its physical configuration or qua its properties as a whole, since both are the same. In general, if the property of being $A$ is the same as the property of being $B$, then all the effects that an object brings about qua being $A$ are the effects that it brings about qua being $B$, and vice versa.

One can thus not trace the eliminativism problem back to the identity claim as such. On the contrary, the mentioned problem is a consequence of the theory of properties against the background of which this identity claim is conceived. The claim of identity on its own does not say much. One has to show how the properties of complex objects on which the special sciences focus can be identical with physical properties. That is why the premises of the causal theory of properties and properties as modes or tropes are crucial for the argumentation of this paper. The properties of complex objects with which the special sciences deal are a paradigmatic example of causal properties. The only reason why we admit these properties is that complex objects have certain specific effects as a whole. The claim of these properties being identical with physical properties is therefore intelligible if and only if those physical properties are causal properties as well, instead of being pure qualities. Otherwise, one would be committed to the consequence that certain configurations of physical properties, which are not causal as such, make true certain causal descriptions of the special sciences, but that there are no causal properties of the objects to which the special sciences refer (see the discussion of Lewis' realizer functionalism above). An eliminativist consequence hence arises if and only if one presupposes a non-causal theory of properties as pure qualities.

The nominalist premise of properties being modes is as important as the premise of the causal theory of properties in order to make this position available. If properties were universals, then the properties of complex objects as a whole on which the special sciences focus could not be identical with physical properties. The reason why there are special sciences that focus on these properties is that the classifications that introduce these sciences in order to seize these properties capture significant similarities that are not expressed by the physical classification of these objects according to their composition. In other words, complex objects that differ in their physical composition can have significant causal 
properties as a whole in common. If these properties were universals, they could therefore not be identical with physical properties qua universals due to multiple realization.

If, by contrast, properties are not universals, but modes, it is no problem how causal properties that complex objects have as a whole can be identical with configurations of physical properties: the manner in which a complex object is insofar as it is the power to produce certain specific effects as a whole is the manner in which it is insofar as it is a configuration of physical properties. These are two different descriptions (concepts, predicates) of one and the same way (mode, trope) in which a complex object is.

The argumentation according to which one can vindicate the causal efficacy of the properties on which the special sciences focus if and only if one conceives these properties as being identical with physical properties is associated with the works of Jaegwon Kim in the contemporary discussion (see notably the books Kim, 1998, and, 2005). On the one hand, Kim tends to conceiving all properties in a causal manner (e.g. 2005, 159), and he rejects the Humean regularity theory of causation, at least as far as mental causation is concerned (Kim, 2007 and 2009); on the other hand, his position comes in the end close to the functionalism of David Lewis: Kim draws the consequence that there are in the last resort no properties that correspond to the descriptions of the special sciences; these descriptions refer to tokens of fundamental physical properties (see Kim, 1998, 111, and, 2005, 26, 58 as well as 2008, 108112). Kim adopts Lewis' conception of a local, species-specific reduction (Kim, 1998, in particular 93-95, and, 2005, in particular 25). However, in that manner, Kim's position ends up in the eliminativism horn of the dilemma of the standard versions of functionalism. The position argued for in this paper can be received as a further development of Kim's position, having the aim in view to develop a version of functionalism that avoids the mentioned dilemma by being a conservative reductionism.

Like Kim, John Heil (2003) argues against the conception of there being different ontological levels of properties out there in the world. Heil also maintains that the properties which are supposed to exist on higher levels can only be causally efficacious by being identical with physical properties. Going beyond Kim, Heil argues in favour of a version of the causal theory of properties, and he conceives properties as modes. The position developed in this paper therefore is close to the one of Heil. However, my main criticism of Heil's ontology is that he does not develop the consequences that his premises would allow him to draw: his view finally amounts to the conclusion that the functional properties of the special sciences do not exist, there being only the fundamental physical properties (see Heil, 2003, 45, 153, and, 2006, 18-21, for a clear and concise statement, as well as Esfeld, 2006, on this consequence of Heil's position). Again, the threat of the dilemma between eliminativism and epiphenomenalism is obvious.

The causal theory of properties is associated in particular with Sydney Shoemaker's paper "Causality and properties" (1980). In later work, Shoemaker argues for a view according to which the properties on which the special sciences focus are realized by physical properties without being identical with them: in brief, the powers that characterize a property of the special sciences are a subset of the powers that characterize the respective physical realizer properties (see Shoemaker, 2007, chapter 2, especially 11-14). Following Yablo (1992), Shoemaker draws a distinction between determinable and determinate properties and takes this distinction to illustrate that view: the powers that characterize a determinable property are a subset of the powers that characterize the respective determinate realizer properties. Thus, 
the causal powers that characterize the property of being blue are a subset of the causal powers that characterize the property of being marine blue: marine blue has all the causal powers of blue and further powers, namely those ones that distinguish marine blue from, for instance, cobalt blue.

However, by making that ontological distinction between properties, Shoemaker runs into the same problem as the role functionalism of Putnam and Fodor. As Carl Gillet and Bradley Rives (2005, section 3) point out, the determinate or realizer properties include by definition all the powers of the respective determinables. Consequently, the determinate properties are sufficient to bring about all the effects that the determinables could cause. Unless one acknowledges token identity between realized and realizer properties, one thus faces again the epiphenomenalism objection that haunts role functionalism. That objection could only be avoided by either admitting systematic overdetermination or by accepting interactionism, thus rejecting the causal completeness of the physical domain (McLaughlin, 2007, interprets Shoemaker's position in that latter way; see also the emergentism that Gillet, 2006, contemplates).

It can with reason be maintained that the differentiation between determinables and determinates is not an ontological one between properties that there are in the world, but concerns only concepts and descriptions. The predicates that we use in order to describe the properties in the world can be determinable or determinate, such as the predicates "blue" and "marine blue". The properties that there are in the world are all determinate ones (see Gillet and Rives, 2005). Being blue or being marine blue are in no manner different properties that there are in the world. One and the same property in the sense of a way (mode) in which an object is can be described in a precise manner by using the predicate "marine blue" and in a less precise manner by using the predicate "blue".

Shoemaker's claim that a physical property that realizes a property in the domain of a special science brings about the effects that characterize the latter property only in virtue of a subset of its causal powers is disputable, if one bears in mind that what is causally efficacious are property tokens, not types. The properties of the special sciences cannot be realized by single physical properties, but only by configurations of physical properties. Any property token of the special sciences can cause the effects that characterize the property type in question in the vocabulary of a special science only by bringing about the effects that a certain configuration of physical properties produces as a whole. For instance, any gene token can produce the specific protein that it brings about in a certain situation only by having all the molecular effects that a certain DNA configuration has as a whole in that situation, for it is through those effects that the protein comes into being. To take another example, any pain token can cause the specific pain behaviour that it brings about in a certain situation only by producing the neuronal effects that a certain configuration of neurons has as a whole in that situation because it is through those effects that the pain behaviour comes about. The properties on which the special sciences focus hence are in the same manner determinate properties as are the physical properties. It is only that their descriptions in the vocabulary of a special science are not as detailed as physical descriptions.

This conclusion could be avoided by admitting token multiple realization, that is, maintaining that, for instance, one and the same pain token can be realized by a neuronal configuration of another type in another possible world (Yablo, 1992, endorses token multiple realization). However, if one subscribes to this idea, one is committed to the position that 
each token of a functional property possesses a primitive thisness, since its being is independent of the physical configuration that realizes it in a given world. In this case, there are two property tokens $a$ and $b$ of the same property type in the domain of a special science, in the world $w_{1}, a$ is realized by a physical configuration of type $P_{1}$, and $b$ is realized by a physical configuration of type $P_{2}$. In the world $w_{2}$, by contrast, it is $a$ that is realized by a physical configuration of type $P_{2}$, and it is $b$ that is realized by a physical configuration of type $P_{1}$. The only difference between these two worlds is a swap of $a$ and $b$. One thus is committed to haecceitism: worlds are recognized as being different whose only difference consists in a swap of individuals, without there being any qualitative difference between them. Haecceitism is widely considered to be an implausible position for this reason (see notably Lewis, 1986b, chapter 4.4, and 2009, section 4).

This short discussion shows that newer version of functionalism that are proposed in the contemporary literature also run into the dilemma of epiphenomenalism and eliminativism, which the classical versions of functionalism of Putnam and Fodor on the one hand and Lewis on the other face. The way out of this dilemma consists in proposing a causal theory of properties together with a theory of properties as modes and to base on this view of properties the claim of the properties on which the special sciences focus being identical with configurations of physical properties.

\section{Ontological and epistemological reductionism}

Token identity in the sense of an identity of properties as tropes or modes as a proposal to resolve the problem of the causal efficacy of the properties on which the special sciences focus is not new. Notably David Robb (1997) has argued for token identity on the basis of a metaphysics of properties as tropes. What the present proposal adds to Robb is a causalfunctional view of all properties, supported by independent arguments. Nonetheless, one may object that this move is not sufficient to solve the mentioned problem: the metaphysics of properties as particulars (modes or tropes) is employed in this context because there is no type identity between types of the special sciences - such as biological or psychological types and physical types due to multiple realization. One can in this context object the following: insofar as there is only a reduction of tokens, but not of types, the problem remains whether the properties on which the special sciences focus cause anything qua biological, or mental properties, etc.

Let us briefly consider the background of that problem: Donald Davidson (1970) claims in his famous paper "Mental events" that mental events are identical with physical events. More precisely, all events admit a physical description, and some events admit also a mental description. It is not possible to reduce the mental to a physical description. This position is widely recognized to fail due to the following objection: it cannot show that events cause anything insofar as they are mental events (see the papers in Heil and Mele, 1993).

The position put forward in this paper differs from the one of Davidson in that identity applies to property tokens in the sense of modes or tropes. Nonetheless, Paul Noordhof (1998) objects to Robb (1997) that in the same way as it is reasonable to ask whether a Davidsonian mental event causes anything qua mental, it is reasonable to ask whether a mental trope causes anything qua being a trope of a mental type (see, as regards this objection, also Kistler, 2009, chapter 5.2). Robb (2001) retorts that if identity is applied to those entities in virtue of which an object or event causes something, namely properties in the sense of tropes, it makes 
no sense to raise the qua-question for these entities, since they are already the most finegrained ones (cf. also Whittle, 2007, section 4).

Even though that reply is correct, there remains a problem. If all that exists in the world are particulars (objects and their modes), then types are concepts that seize salient similarities among the ways objects are (natural kinds). As regards the mentioned ways in which complex physical objects exist, these modes make true descriptions in terms of physical concepts that focus on their composition as well as descriptions in terms of concepts of the special sciences that focus on the salient effects that they bring about as a whole in a given environment. Multiple realization is the epistemological fact that modes coming under one single concept of the special sciences often come under different physical concepts. The concepts of the special sciences and the corresponding physical concepts differ not only in meaning, but they are also not coextensive.

On the one hand, not only the physical concepts, but also the concepts of the special sciences possess a scientific quality, consisting in these concepts figuring in law-like generalizations that are projectible, support counterfactuals and provide causal explanations. On the other hand, not only Davidson in his "Mental events", but also most of the philosophers who favour token identity in the fine-grained sense of identity of properties as particulars (modes, tropes) maintain that the descriptions (laws, theories) in which concepts that are proper to the special sciences figure cannot be reduced to physical descriptions (laws, theories) (or remain at least neutral with respect to that latter point). In other words, they defend ontological reductionism combined with an epistemological anti-reductionism (or at least combined with neutrality as regards epistemological reductionism).

However, in that case, the problem that haunts Davidson and that Noordhof raises against Robb reappears: it has to be possible to relate the different descriptions in a systematic, reductive manner, if they are descriptions that are made true by one and the same way an object is and if each of them is to provide for law-like generalizations that are projectible, support counterfactuals and yield causal explanations. Otherwise, it could not be vindicated that these descriptions are about the same entities in the fine-grained sense of modes instead of being about different properties that objects have, that is, different ways in which they are. Consequently, the position would end up either in property dualism with the threat that the ways objects are insofar as they make true descriptions of the special sciences are epiphenomenal, or in eliminativism as regards the scientific quality of the descriptions in terms of the special sciences.

The argumentation set out in this paper hence is not complete as yet. The ontological reductionism proposed in this paper stands or falls together with an epistemological reductionism. Multiple realization prevents the types in which the special sciences trade from being identical with physical types. Nonetheless, one has to achieve some sort of type reduction, that is, provide for a way that enables in principle the reduction of the descriptions (laws, theories) of the special sciences to physical descriptions (laws, theories) in order to retain the scientific quality of the former ones. Christian Sachse shows in his contribution to this volume how this can be done against the background of the causal theory of properties. Thus, if the argumentation in this paper and the following one is on the right track, the causal theory of properties opens up the way both for a conservative ontological reductionism and a conservative epistemological reductionism. 


\section{Bibliography}

Armstrong, David M., 1999: The causal theory of properties: properties according to Shoemaker, Ellis, and others. In: Philosophical Topics 26, pp. 25-37.

Bennett, Karen, 2003: Why the exclusion problem seems intractable, and how, just maybe, to tract it. In: Noûs 37, pp. 471-497.

Bickle, John, 1998: Psychoneural reduction: the new wave. Cambridge (Massachusetts): MIT Press.

Bird, Alexander, 2007a: Nature's metaphysics. Laws and properties. Oxford: Oxford University Press.

- 2007b: The regress of pure powers? In: Philosophical Quarterly 57, pp. 513-534.

Black, Robert, 2000: Against quidditism. In: Australasian Journal of Philosophy 78, pp. 87-104.

Block, Ned, 1990: Can the mind change the world? In: Boolos, George (ed.): Meaning and method. Essays in honor of Hilary Putnam. Cambridge: Cambridge University Press, pp. 137-170.

Busse, Ralf, 2008: Fundamentale Eigenschaften und die Grundlagen des Ähnlichkeitsnominalismus. In: Philosophia Naturalis 45, pp. 167-210.

Davidson, Donald, 1970: Mental events. In: Foster, L.; Swanson, J. W. (eds.): Experience and theory. Amherst: University of Massachusetts Press, pp. 79-101. Reprinted in Davidson, Donald, 1980: Essays on actions and events. Oxford: Oxford University Press, pp. 207-225.

Esfeld, Michael, 2006: From being ontologically serious to serious ontology. In: Esfeld, Michael (ed.): John Heil. Symposium on his ontological point of view. Frankfurt (Main): Ontos, pp. 191-206.

- 2007: Mental causation and the metaphysics of causation. In: Erkenntnis 67, pp. 207-220.

- 2010: Causal overdetermination for Humeans? In: Metaphysica 10, DOI: 10.1007/s12133-010-0061-3.

- and Sachse, Christian, 2010: Kausale Strukturen. Einheit und Vielfalt in der Natur und den Naturwissenschaften, Berlin: Suhrkamp 2010. English version Conservative reductionism. Forthcoming New York: Routledge spring 2011.

Fodor, Jerry A., 1974: Special sciences (or: The disunity of science as a working hypothesis). In: Synthese 28, pp. 97-115.

Gillet, Carl, 2006: Samuel Alexander's emergentism: or, higher causation for physicalists. In: Synthese 153, pp. 261-296.

- 2007: A mechanist manifesto for the philosophy of mind: a third way for functionalists. In: Journal of Philosophical Research 32, pp. 21-42.

Gillet, Carl; Rives, Bradley, 2005: The non-existence of determinables: or, a world of absolute determinates as default hypothesis. In: Noûs 39, pp. 483-504.

Heil, John, 2003: From an ontological point of view. Oxford: Oxford University Press.

- 2006: On being ontologically serious. In: Esfeld, Michael (ed.): John Heil. Symposium on his ontological point of view. Frankfurt (Main): Ontos, pp. 15-27.

- 2009: Obituary. C. B. Martin. In: Australasian Journal of Philosophy 87, pp. 177-179.

Heil, John; Mele, Alfred (eds.), 1993: Mental causation. Oxford: Oxford University Press.

Kim, Jaegwon, 1998: Mind in a physical world. An essay on the mind-body problem and mental causation. Cambridge (Massachusetts): MIT Press.

- 2005: Physicalism, or something near enough. Princeton: Princeton University Press.

- 2007: Causation and mental causation. In: McLaughlin, Brian P.; Cohen, Jonathan (eds.): Contemporary debates in philosophy of mind. Oxford: Blackwell, pp. 227-242.

- 2008: Reduction and reductive explanation: is one possible without the other?" In: Hohwy, Jacob and Kallestrup, Jesper (eds.): Being reduced. Oxford: Oxford University Press, pp. 93-114.

- 2009: Mental causation. In: McLaughlin, Brian, Beckermann, Ansgar and Walter, Sven (eds.): The Oxford handbook of philosophy of mind. Oxford: Oxford University Press, pp. 29-52.

Kistler, Max, 2009: La cognition entre réduction et émergence. Etude sur les niveaux de réalité. Paris: Syllepse.

Langton, Rae; Lewis, David, 1998: Defining 'intrinsic'. In: Philosophy and Phenomenological Research 58, pp. 333-345. Reprinted in Lewis, David, 1999: Papers in metaphysics and epistemology. Cambridge: Cambridge University Press, pp. 116-132. 
Lewis, David, 1980: Mad pain and Martian pain. In: Block, Ned (ed.): Readings in the philosophy of psychology. Volume 1. London: Methuen, pp. 216-222. Reprinted in Lewis, David (1983): Philosophical papers. Volume 1. Oxford: Oxford University Press, pp. 122-130.

- 1986a: Philosophical papers. Volume 2. Oxford: Oxford University Press.

- 1986b: On the plurality of worlds. Oxford: Blackwell.

- 1994: Lewis, David: Reduction of mind. In: Guttenplan, Samuel H. (ed.): A companion to the philosophy of mind. Oxford: Blackwell, pp. 412-431.

- 2009: Ramseyan humility. In: Braddon-Mitchell, David; Nola, Robert (eds.): Conceptual analysis and philosophical naturalism. Cambridge (Massachusetts): MIT Press, pp. 203-222.

Locke, Dustin, 2009: A partial defense of Ramseyan humility. In: Braddon-Mitchell, David; Nola, Robert (eds.): Conceptual analysis and philosophical naturalism. Cambridge (Massachusetts): MIT Press, pp. 223-241.

Loewer, Barry, 2007: Mental causation, or something near enough. In: McLaughlin, Brian P.; Cohen, Jonathan (eds.): Contemporary debates in philosophy of mind. Oxford: Blackwell, pp. 243-264.

Martin, C. B., 1997: On the need for properties: the road to Pythagoreanism and back. In: Synthese 112, pp. 193231.

McLaughlin, Brian P., 2007: Mental causation and Shoemaker-realization. In: Erkenntnis 67, pp. 149-172.

Mumford, Stephen, 1998: Dispositions. Oxford: Oxford University Press.

Noonan, Harold W., 2010: Bird against the Humeans. In: Ratio 23, pp. 73-86.

Noordhof, Paul, 1998: Do tropes resolve the problem of mental causation? In: Philosophical Quarterly 48, pp. 221-226.

Putnam, Hilary, 1967 / 1975: The nature of mental states. In: Putnam, Hilary, 1975: Mind, language and reality. Philosophical papers. Volume 2. Cambridge: Cambridge University Press, pp. 429-440. First published as Psychological predicates. In: Capitan, W. H.; Merrill, D. D. (eds.), 1967: Art, mind and religion. Pittsburgh: University of Pittsburgh Press.

Robb, David, 1997: The properties of mental causation. In: Philosophical Quarterly 47, pp. 178-194.

- 2001: Reply to Noordhof on mental causation. In: Philosophical Quarterly 51, pp. 90-94.

Shoemaker, Sydney, 1980: Causality and properties. In: van Inwagen, Peter (ed.): Time and cause. Dordrecht: Reidel, pp. 109-135. Reprinted in Shoemaker, Sydney, 1984: Identity, cause, and mind. Philosophical essays. Cambridge: Cambridge University Press, pp. 206-233.

- 2007: Physical realization. Oxford: Oxford University Press.

Strawson, Galen, 2008: The identity of the categorical and the dispositional. In: Analysis 68, pp. 271-282.

Whittle, Ann, 2007: The co-instantiation thesis. In: Australasian Journal of Philosophy 85, pp. 61-79.

- 2008: A functionalist theory of properties. In: Philosophy and Phenomenological Research 77, pp. 59-82.

Yablo, Stephen, 1992: Mental causation. In: Philosophical Review 101, pp. 245-280. 